\section{AB007. Worse skin disease severity may distinguish patients who progress from cutaneous lupus erythematous to systemic lupus erythematous}

\author{
Frances Walocko ${ }^{1}$, Samantha Black ${ }^{1}$, Scott Anderson ${ }^{1}$, \\ Xilong $\mathrm{Li}^{2}$, Beverley Adams-Huet ${ }^{2}$, Benjamin Chong ${ }^{1}$ \\ ${ }^{1}$ Department of Dermatology, University of Texas Southwestern \\ Medical Center, Dallas, TX, USA; ${ }^{2}$ Department of Population and \\ Data Sciences, University of Texas Southwestern Medical Center, \\ Dallas, TX, USA \\ Correspondence to: Benjamin Chong. Department of Dermatology, \\ University of Texas Southwestern Medical Center, 5323 Harry Hines \\ Blvd., Dallas, TX 75390-9069, USA. \\ Email: Ben.Chong@UTSouthwestern.edu.
}

Abstract: Up to $20 \%$ of patients with cutaneous lupus erythematosus (CLE) will develop systemic lupus erythematosus (SLE). Prior studies identified baseline clinical characteristics associated with progression to SLE, including generalized discoid lupus (DLE) and arthritis. Factors that change over time including skin disease severity have not been well studied. The objective of this retrospective cohort study was to identify fixed and variable risk factors that predispose patients with CLE to develop SLE. Sixty-five patients with CLE followed for a minimum of six months from December 2008 and August 2019 were included. Eleven progressed from CLE to SLE (16.9\%), while $54(83.1 \%)$ remained CLE only. Demographic and clinical data from both groups were compared using Fisher's exact test or Wilcoxon Rank Sum test. At baseline, CLE to SLE patients had greater American College of Rheumatology SLE diagnostic criteria than CLE only [median 3 (IQR, 3-3) vs. 2 (1-3); $\mathrm{P}=0.003$ ] and lower (worse) physician global assessment (PGA) overall skin scores [7
(5-7) vs. 8 (7-9); $\mathrm{P}=0.02]$. Generalized DLE $(\mathrm{n}=6)$ was more associated with progression to SLE $v$ s. localized DLE $(\mathrm{n}=22)(\mathrm{P}=0.048)$. There were no significant differences in Cutaneous Lupus Erythematosus Activity and Severity Index (CLASI) scores and Systemic Lupus Erythematosus Disease Activity Index (SLEDAI) scores. Longitudinally, CLE to SLE patients had greater CLASI scores at year 1 [10 (4-17) vs. 2 (0-4.5); $\mathrm{P}=0.02]$ and year 3 [19 (12-16) vs. 0 $(0-2) ; \mathrm{P}=0.03]$. PGA overall skin scores were worse in CLE to SLE patients at year 1 [5 (3-6) vs. 8 (7-9); $\mathrm{P}=0.003]$ and year 3 [5 (5-5) vs. 9 (8-10); $\mathrm{P}=0.04]$. CLE to SLE patients had greater SLEDAI scores at year 3 [4 (4-4) vs. 0 (0-2); $\mathrm{P}=0.03]$. Limitations include small sample size and missing follow-up visits. Our data suggests persistently worse skin disease activity may separate patients who progress from CLE to SLE from those who remain CLE. Further longitudinal data is being collected to verify these results. If validated, CLE patients with persistently high skin disease activity need close monitoring for SLE progression.

Keywords: Cutaneous lupus erythematosus (CLE); cutaneous lupus disease area and severity index; longitudinal; systemic lupus erythematosus (SLE); disease activity; disease damage

doi: 10.21037/atm.2021.AB007

Open Access Statement: This is an Open Access article distributed in accordance with the Creative Commons Attribution-NonCommercial-NoDerivs 4.0 International License (CC BY-NC-ND 4.0), which permits the noncommercial replication and distribution of the article with the strict proviso that no changes or edits are made and the original work is properly cited (including links to both the formal publication through the relevant DOI and the license). See: https://creativecommons.org/licenses/by-nc-nd/4.0/.

Cite this abstract as: Walocko F, Black S, Anderson S, Li $\mathrm{X}$, Adams-Huet B, Chong B. Worse skin disease severity may distinguish patients who progress from cutaneous lupus erythematous to systemic lupus erythematous. Ann Transl Med 2021;9(5):AB007. doi: 10.21037/atm.2021.AB007 